\begin{tabular}{|c|c|c|}
\hline $\begin{array}{l}\text { PUCRS } \\
\text { PUCR }\end{array}$ & $\begin{array}{l}\text { ESCOLA DE } \\
\text { HUMANIDADES }\end{array}$ & $\begin{array}{l}\text { Revista de Cultura e Literaturas de Língua Portuguesa } \\
\text { Navegações, Porto Alegre, v. 14, n. 2, p. 1-8, jul.-dez. } 2021 \\
\text { e-ISSN: 1983-4276 ISSN-L: 1982-8527 }\end{array}$ \\
\hline $\mathrm{tp}: / / \mathrm{dx}$ & org $/ 10.15448 / 1983-4276.2021 .2$ & \\
\hline
\end{tabular}

SEÇÃO: ENSAIOS

\title{
As fronteiras do opaco ${ }^{1}$
}

The Boundaries of the Opaque

\section{Benhur Bortolotto ${ }^{2}$}

orcid.org/0000-0001-6984-5544 benhur.bortolotto@ufrgs.br

Recebido em: 7 out. 2020. Aprovado em: 2 jul. 2021. Publicado em: 16 dez. 2021.

\section{(c) (i)}

Artigo está licenciado sob forma de uma licença Creative Commons Atribuição 4.0 Internacional.
Resumo: O tópico central de O prisioneiro, novela de Erico Verissimo, é, segundo o autor, a estupidez humana em muitos aspectos. Sua declaração é categórica, mas vaga. O texto de Verissimo tem como temas principais o racismo e a guerra, com suas violências e violações. Mas se em aspectos valorativos ambos, a guerra e o racismo, mantêm vizinhanças com a estupidez, sua unificação demanda menos subjetividade. A passagem daquilo que os aproxima para aquilo que os iguala é a função ética do libelo humanista do autor. Este artigo se dedica à sua contraparte literária, de caráter epistêmico; tento mostrar que a estrutura da novela permite delinear, para além da ilegitimidade das ações políticas em questão, a fragilidade e a insuficiência das próprias crenças com as quais se pretende fundamentá-las.

Palavras-chave: Erico Verissimo. Vietnã. Humanismo.

Abstract: The central topic of The Prisoner, novel by Erico Verissimo, is, according to the author, human stupidity in its many forms. The statement is categorical but vague. The novel's main themes are the racism and the war, with its violence and violations. But if in value aspects both war and racism are very close with stupidity, their unification demands less subjectivity. Passing from what brings them close to what make them equals is the ethical function of the author's humanist advocacy. This article intends to presentes, as literary counterpart of that advocacy, an epistemic premise; I try to show that the novel's structure allows to delineate, besides the illegitimacy of the political actions in question, the fragility and insufficiency of the very beliefs with which it is intended to be founded.

Keywords: Erico Verissimo. Vietnam. Humanism.

\section{Introdução}

Os problemas politicos pautados por Erico Verissimo em O prisioneiro (VERISSIMO, 2008) são os problemas políticos da geração que viveu o final da década de 1960 em condições de tomar partidos. Opiniões emitidas pelas personagens registram, com boa envergadura, ideias disponiveis ao debate da época. O tópico central é, segundo o autor, a estupidez humana em muitos aspectos (VERISSIMO, 2008, p. 9). Sua declaração é categórica, mas vaga.

A saudável ojeriza que as boas consciências humanistas tenham aos procedimentos da segregação étnica e das imposições por força bruta talvez torne razoável que não se demande maiores explicações sobre a temática alegada da obra. Afinal, trata-se de um texto sobre o racismo e, também, sobre a guerra, com suas violências e violações. Mas

Esta pesquisa foi produzida com apoio financeiro da Coordenação de Aperfeiçoamento de Pessoal de Nivel Superior (CAPES), Brasil. Grande Área: Ciências Humanas.

2 Universidade Federal do Rio Grande do Sul (UFRGS), Porto Alegre, RS, Brasil. 
se em aspectos valorativos ambos, a guerra e o racismo, mantêm vizinhanças com a estupidez, sua unificação demanda menos subjetividade. A passagem daquilo que os aproxima para aquilo que os iguala é a função ética do libelo humanista de Erico Verissimo. Sua contraparte literária, contudo, é de caráter epistêmico.

O que tentarei, nas três seções deste ensaio, é mostrar que a estrutura da novela permite delinear, para além da ilegitimidade das ações políticas em questão, a fragilidade e a insuficiência das próprias crenças com as quais se pretende fundamentá-las.

\section{Retrato de uma especificidade}

Ambientada em um pais que se distingue, assim como as personagens, meramente por sua posição, a novela abdica dos nomes próprios. $O$ coronel, o major, o tenente, a professora, o sargento, o médico e o prisioneiro; todos surgem como peças alegóricas de uma engrenagem trágica. Resultado das dificuldades da língua estrangeira, o K. da prostituta por quem o tenente se apaixona é o esboço solitário de um substantivo mais pessoal.

No que se vê - pela compleição arquitetônica, pela época, pela cultura e pelos interesses mobilizados -, o Vietnã, Erico Verissimo tenta registrar um drama menos localizado, de referência mais ampla. O conflito armado é objeto e é, também, a pretensão de uma metáfora com a qual o autor tenta, talvez, aludir aos efeitos da guerra, assolapadora de individualidades. Mas a eficácia da generalização, qualquer que seja seu propósito, mostra-se limitada. É porque os êxitos da novela, seu alcance e insaturação, residem mais na capacidade que o texto tem de revelar certas peculiaridades da guerra do Vietnã do que os já elaborados dramas das guerras em geral, como em Saga (1940). A guerra de Erico Verissimo em O prisioneiro é um fato que compartilha com o cenário - a velha cidade imperial "a sufocar à míngua de oxigênio" (VERISSIMO, 2008, p. 16) um movimento próprio, de uma economia que se adequou às contingências da intervenção.

Nas primeiras três páginas da novela, compõe- -se o pano de fundo urbano, cuja organicidade é já o indice de uma característica bastante peculiar do conflito retratado: ao aproximar ocupantes e ocupados, a empreitada intervencionista demanda um afastamento que viabilize as violências e arbitrariedades das funções opressoras dos primeiros. 0 convívio entre os uns e outros que a nacionalidade, a ideologia e a cultura estabelecem converte-se em uma espécie de teste à rigorosa, mas abstrata, demarcação de suas diferenças constitutivas.

Manifestam-se, então, a partir da guerra, duas caracteristicas centrais para a identificação da estrutura do texto. A primeira diz respeito à guerra em si, como conflito de intervenção, cujo propósito alegado não é o de dominar. ${ }^{2}$ Como consequência, há possibilidade de uma aproximação, empática em algum nível, ainda que tópico, entre orientais e ocidentais. A segunda, por sua vez, diz respeito à guerra representada, que surge como pano de fundo dos dramas pessoais trazidos à luz na narrativa. Disso decorre que as ações da novela não são ações de batalha.

Erico Verissimo estabeleceu um rol reduzido de personagens, que sofrem nos interstícios de eventos superlativos. As batalhas épicas só existem como acontecimento emocional: aflição relatada ou expectativa e ansiedade. Mas o texto logra seus maiores êxitos precisamente na medida em que o conflito em si diminui diante da apreciação que se tem do conflito.

A guerra tem sido metáfora de tensões e clivagens de pensamentos fundantes. Desde Heráclito - para quem a guerra é "pai de todas as coisas" (KIRK, 2010, p. 197) e, o impasse, condição de nossa sobrevivência -, até as dialéticas da tradição hegeliana, que encontram no confronto a imagem e a expressão das oposições interdependentes. Mas pretensões arquetípicas padecem de uma insuficiência diante de novas formas de guerra ou, melhor seria dizer, das novas formas de organização social que dão aos conflitos armados dos nossos tempos feições inéditas.

Com a ascensão das democracias liberais, os estridulosos e sucessivos êxitos científicos e no

2 Em um diálogo entre o, a um só tempo, culto e obtuso coronel, burocrata da intervenção, e o major, este primeiro se condói, entre estarrecido e indignado, com a incapacidade que os invadidos têm de perceber que os invasores querem ajudá-los (VERISSIMO, 2008, p. 30-40). 
rescaldo de confrontos de proporções mundiais, separadas por apenas duas décadas, o épico, no século $X X$, evanesce. ${ }^{3}$ Progressivamente, a imagem da guerra adquire força como manifestação de dramas que, não podendo (sob pena de inviabilizar a literatura) ser particulares, são intimos.

$O$ inimigo é cada vez menos distinto. A paulatina universalização do conhecimento e as homogeneizações da vida urbana permitem a apreensão de sujeitos subjacentes a nacionalidades, crenças e ideologias. Ainda: a nacionalidade, no mundo da ascensão das democracias liberais e das sociedades cada vez menos autóctones, deixou de ser o signo de uma segurança ou pertencimento para aqueles a quem as divergências de opinião ou a cor da pele se convertem em pecado ou ameaça.

O tenente, personagem que parte para a guerra para não assumir os dramas, tanto pessoais quanto sociais, de sua condição de negro, faz reverberar, em seu constante e nem sempre consciente desespero, os horrores do confronto num mundo em que as nacionalidades significam cada vez menos. Ele próprio não luta por seu país, mas sim para sair de um país que já não pode lhe oferecer nem uma identidade, nem uma ética.

Noutra formulação: ao esgarçarem-se as noções constitutivas da identidade e, de maneira relevante, da ética do individuo moderno, como eram dominantemente a religião e a pátria, as ações humanas passam a carecer de um caráter reflexivo que já não se escora por inteiro naquilo que, posteriormente Lyotard chamaria de grandes metanarrativas (LYOTARD, 1986). Ignorá-lo é tornar-se, assim como o coronel interventor, uma chacota pronta, ridicularizado em sua ingenuidade e hipocrisia.

Há, assim, um pressuposto para o argumento das próximas seções do texto: o de que a guerra da qual trata $O$ prisioneiro não é a metáfora de um embate entre duas visões distintas de mundo, mas a alegoria de um esfacelamento dos grandes embates épicos entre oposições dadas. Com isso, alegoria também do surgimento, no bojo deste inevitável ocaso, de um drama ético que diz respeito à legitimidade de ações individuais. A guerra é, como observa o coronel, para desagrado de seu temperamento, "demasiadamente fluida e informe" (VERISSIMO, 2008, p. 34).

\section{As diatribes do mesmo}

A novela de Erico Verissimo se organiza em torno de duas diatribes em que são apresentadas, de modo semelhante, as personagens e ideias em pauta. Nesses diálogos, as teias estruturais do texto de Erico revelam, aos poucos, o lastro de sua contundente critica.

Da descrição de uma cena do país invadido parte-se à ação, que evidencia não apenas as rupturas causadas pela intervenção militar mas também um assentamento ou acomodação, derivados das necessidades de se continuar a vida. A impassividade dos asiáticos e os tumultos causados pela presença do invasor compõem o quadro. Após a ação, exógena ao diálogo subsequente, tem-se a caracterização de uma das personagens, a que observa a cena e, em seguida, do ponto de vista desta, a caracterização de seu interlocutor. A fórmula repete-se, estabelecendo o paralelo entre os dois diálogos que constituem o eixo central deste meu argumento.

A primeira diatribe se dá numa conversa entre o coronel interventor e o major. As posições politicas manifestadas por um e outro são os registros parciais; visões dispares de mundo que, ao comporem um discurso fraturado, impedem a totalização de ideias cuja pretensão de universalidade esbarra na mera resistência - validada ou não, seja pela lógica, pela realidade factual ou pelo rigor de sua interpretação.

Por isso o discurso do coronel, no que se pretende caridoso e solidário - "está ao nosso alcance salvar da miséria, da doença e da ignorância este e outros países do mundo igualmente subdesenvolvido" (VERISSIMO, 2008, p. 30) -, faz confundirem-se ingenuidade e cretinice ordinária. Ainda que se pudessem rastrear, sem sombra de

3 Esse século em que tudo é grande: as grandes guerras, os grandes retrocessos, os grandes avanços, as grandes curas, as grandes doenças, as grandes riquezas, as grandes misérias, os grandes contrastes enfim, que terminam por relativizar o grande, apequenando-o (TUTIKIAN, 2019, p. 17) 
dúvidas, nas intenções que mobilizam a intervenção, exclusivamente os mais nobres propósitos; e que tais propósitos fossem levados a cabo sem se corromper pelo preconceito e arrogância de agentes que, como o próprio coronel, veem nos nativos uma "sub-raça que acredita em feiticeiros, médiuns e astrólogos [...] [e] adora Deus na forma de um olho", restaria ainda o problema de que a legitimidade da guerra intervencionista não é, nem pode ser, função de suas supostas intenções.

Note-se que nação não serve para unificar os discursos que, no primeiro diálogo crítico da novela, são contrapostos, uma vez que ambos os interlocutores compartilham uma só pátria. Mesmo a ideologia, que cumpre um papel preponderante no viés pelo qual o coronel avalia a guerra, não se estabelece como perspectiva única entre os dois. Ainda que a novela seja contemporânea ao ápice da tensão ideológica estabelecida entre as duas grandes potências que emergem da Segunda Guerra Mundial, anterior, portanto, à queda do mundo soviético, a narrativa permeia os diálogos com elementos pessoais. A vida privada e as experiências individuais de cada um é que dão, à forja das ideias emitidas, uma circunscrição mais complexa do que a simplista redução a modelos sociais, classes, nacionalidades, religiões ou cores.

o mundo é mais complexo do que isso e a literatura tem tido, inúmeras vezes, mais êxito do que as ciências humanas em compreender esta complexidade. Assim, na primeira das duas diatribes que, em minha leitura, compõem o cerne estrutural do texto, as ideias das personagens dividem espaço com suas histórias pessoais. Não se trata apenas de evidenciar, por comparativos, certa hipocrisia quando o coronel acusa a "frouxidão moral" (VERISSIMO, 2008, p. 28) do major - um sujeito gordo, com físico que não convém a um soldado, adepto de orgias e comilanças -, mas sobretudo de situar as visões de mundo de cada personagem em uma experiência de vida que não se esgota mais nos dois ou três traços que outrora poderiam, talvez, ser decisivos.

Como atenuante da hipocrisia do coronel, valha a desculpa, ainda que canhestra, de que aquilo que the desagrada no major é o desleixo com uma aparência ideal que o coronel, por sua vez, esforça-se para manter. Evidência disto são as cartas não enviadas a sua filha, as traições à esposa, que despreza, e as mágoas de um casamento fracassado, impedido, pelos resquícios de sua criação, de ser levado a termo.

O major, provavelmente à revelia das pretensões do autor, é sua melhor e mais eficaz personagem. Trata-se de um cínico que, em resposta aos símiles animais que o coronel adota para reduzir, em tamanho e valor, o inimigo, oferece-lhe, em recurso da mesma analogia, suas contrapartidas possivelmente positivas: os ardis com que o guerrilheiro asiático se esgueira na cidade dominada pela força e pela já monótona burocracia da intervenção. A lucidez do major, embora cínica, é mais intelectualmente desafiadora do que podem ser as ingênuas ponderações da professora, em resposta ao tenente, na segunda diatribe, uma vez que não se comprometem com respostas ou alternativas. Seu papel é tão somente o de contestar.

As configurações de caráter que emergem da apresentação, mais ou menos simultânea, das ideias e histórias pessoais destas duas personagens, são forçosamente desafiadores em seus paradoxos latentes. O coronel, marido adúltero, homem racista e oficial arrogante, tem, para suas ações, o consolo moral de um molde ideológico. Por mais que se possa, sem muitos esforços argumentativos, evidenciar as frágeis bases de sua ilusão ética, é necessário conceder que, na constituição da personagem, elas operam como consolos de fato eficazes para as premências de sua função profissional, e como justificativas para as ações de toda uma vida. Também por isso the importuna a fluidez de uma guerra que já não se resume ao embate épico entre heróis de mundos tão distintos e inconciliáveis, que só pela deflagração do conflito poderiam interagir.

O major, por sua vez, ao recusar a validade das proposições toscas e pretensiosas de seu superior, ao responder à afirmação (extensa e profusa em exemplos) de que a cultura asiática é uma cultura de crendices com seu sucinto, mas preciso, "nós também temos deuses estranhos" 
(VERISSIMO, 2008, p. 30), abre mão do consolo moral para suas ações. O major, ao cumprir as ordens do coronel, ao desempenhar seu papel de oficial do exército interventor, traz à tona a terrivel ambiguidade que assombrará as demais personagens, ávidas por certezas morais.

No cerne desta primeira discussão está a legitimidade da guerra. De modo fluido, o texto mobiliza justificativas éticas (as boas intenções que se pretende poder atribuir aos invasores), políticas e epistêmicas (o papel civilizatório da superpotência imperialista que se pretende hegemônica).

A segunda diatribe, por sua vez, mobiliza os mesmos temas e apresenta ideias parecidas. São, portanto, paralelas, ainda que ofereçam desdobramentos distintos. Se as prédicas apresentadas, em grande parte, repetem-se, o que as distingue e permite novas reflexões é o modo como Erico Verissimo as relaciona com as personagens que as produzem.

As peculiaridades do drama racial que caracteriza o tenente são um retrato esquemático das questões que ganhavam grande relevância no debate dos direitos civis nos Estados Unidos na década de 1960 e merecem anotações específicas na seção seguinte. Por ora, a fim de caracterizar a função desempenhada pela professora, o que vale observar, sobre o tenente, seu interlocutor, é que este projeta sobre os asiáticos manifestações de um racismo em muito conforme ao que sofreram e sofrem os negros americanos e que, na ocasião do interrogatório do prisioneiro, converter-se-á na máxima sob a qual se organizam suas ações. Mobiliza, como premissa em favor da necessidade de uma tutela do ocidente sobre os povos asiáticos, uma indissociável relação entre a pobreza intelectual (evidenciada, a seu ver, pela cultura mítica) e o despreparo para a democracia. Repete-se, nesta segunda diatribe, a relação gravitacional que põe, na órbita do direito de invadir e tutelar, uma superioridade cultural. "Nós também temos deuses estranhos" (VERISSIMO, 2008, p. 30), lembrara, ao coronel, o major, deixando claro que certas distinções demandam uma boa dose de arbitrariedade.

Quem resiste a suas certezas é a professora, que surge como porta-voz do autor e, no to- cante ao conflito ideológico, sintetiza a máxima da novela, especificamente, e da obra de Erico Verissimo, como um todo: "detesto qualquer tipo de totalitarismo seja qual for seu disfarce ou pseudônimo" (VERISSIMO, 2008, p. 59).

É ela quem põe a indagação sobre quem e como se vai decidir que povos estão ou não maduros para reivindicar a autonomia de suas escolhas. O juizo das partes envolvidas, palestra a professora, não pode ser imune a interesses que, via de regra, se imiscuem de modo sorrateiro e conspurcam a objetividade alegada de decisões pretensamente caridosas. Ao tenente, ela apresenta a guerra como continuação dosjogos de vaidade pessoal e poder político, como continuação do comércio, como imposição de valores que propagam e sustentam as estruturas do poder dominante.

Mas sua cuidadosa e quase irretocável reflexividade é frágil. Nobre de cargo e de espírito, a professora é quase um móbile com o propósito de seduzir por uma temperança que não se abala, mas também não convence. No aspecto realista da obra de Erico Verissimo, a personagem é, dentre todas, a mais incompleta. Seu raciocínio ensaístico carece dos contextos psicológicos que, às demais, conferem temperamento e contingências, e, com eles, o vigor e a veracidade de suas respectivas opiniões. Desvencilhado de uma parcialidade ideologizada, seu discurso perde o lastro das até então inevitáveis parcialidades psicológicas. Por isso o autor precisa, para estabelecer o indice de inegável bondade da personagem, recorrer ao lugar-comum das ações simbólicas da caridade despretensiosa. O recurso, aliás já usado por Erico Verissimo, como, por exemplo, em Saga (VERISSIMO, 1995), com Fernanda, registra o que permanece como limitação, no tocante ao traçado psicológico das personagens, de um dos mais prolíficos e inteligentes autores brasileiros.

Por isso o major, como contraponto a certezas ilusórias, soa mais contundente. Suas afirmações impõem perguntas às quais suas ações não respondem com a facilidade tacanha de benemerências sem contexto. $O$ cinismo de seu caráter surge como um dado empírico acerca da 
natureza humana e das intransponiveis limitações éticas do individuo compelido à ação.

A composição alegórica da novela sem nomes é reforçada, em detrimento de sua elegância realista, pelo minimalismo psicológico da professora. As duas diatribes que apresentei aqui, no entanto, sustentam um desfecho poderoso em que os temas do livro adquirem, com admirável precisão e rigor, o caráter revelador da boa literatura.

\section{0 mais profundo é a pele}

No centro da trama, está o tenente, para quem a guerra é uma espécie de fuga da luta racial que se passa em seu país de origem e que o atravessa de modo irrevogável. Para fugir de sua condição étnica, priva-se do dinheiro da esmola, priva-se do orgulho e do apreço à generosidade do pai negro, priva-se do lar em que a mãe branca não permite que se converta em uma casa de brancos. Torna-se, ele próprio, uma espécie de prisioneiro de um racismo ameaçador que não pode ser abandonado no país longínquo, cuja grandeza acredita estar ajudando a defender e propagar. A luta, como oficial temporário do exército da potência interventora, a civilizar os povos inferiores, serve como um arremedo da posição de superioridade que inveja, mas nunca alcança. Tornou-se feição de seu espírito ser a régua da incontornável superioridade alheia. Por isso, sente-se constantemente coagido e responde a essas coações empreendendo novas e sucessivas fugas.

O tenente e o coronel compactuam de um apreço pelas aparências que a obra revela com inabalável vigor. É na aparência, em sua mais tênue e tópica linha, que convergem as justificativas éticas para suas ações e a miséria emocional de suas vidas pessoais. Vidas em que a falta de sentido faz ser possivel que se projete, na intervenção militar, simulacros de propósitos mais nobres e menos práticos do que aqueles elencados pela professora. Assim, do mesmo modo que, na visão do coronel, o major peca por não ter corpo de soldado; para o tenente, a superioridade é do branco agressor, que espanca e humilha seu pai, e não de seu pai, homem negro que, mesmo alquebrado pelas violências sistemáticas de uma vida de abusos, pessoais e sociais, resguarda um principio inviolável de dignidade.

"O que há de mais profundo no homem é a pele", escreve Paul Valéry (1960, p. 215), ciente de que a fronteira do indivíduo com o mundo existe, mas não é intransponivel. Do texto de Erico Verissimo emergem, constantemente, exemplos de uma zona de indiscernibilidade que o autor não pretende extinguir. Pouco importa definir se o racismo endêmico de uma sociedade estruturada na segregação é o que, de modo cabal, condiciona o tenente a ver superioridade na violência do branco e não no espírito generoso de seu pai negro. Assenti-lo seria, no aspecto individual, negar a este pai o vigor de seu espirito, e, no aspecto social, negar às minorias oprimidas o protagonismo e a capacidade de lutar para o fim das opressões, condenados que estariam, individuos e comunidades, a acreditarem no valor absoluto dos signos arbitrários de seus opressores. As aparências, tão importantes na constituição das respectivas visões de mundo destas duas personagens, o coronel e o tenente, também são, pelo que têm de porosidade, o cerne das muitas ironias do texto.

O jovem oficial, psicólogo do exército em função catequizadora das mentes intelectualmente despreparadas do país oriental, tem, gravada em sua personalidade, a fobia constante de ser discriminado. De tal monta é seu sofrimento, que foge da própria raça indo para uma guerra racista que, como demonstram seus discursos, ele nem bem entende. Mas prefere a guerra à confrontação de sua identidade. Flerta, na modorra do catre, com a autoimolação dos insetos enquanto a memória dos abusos sociais da infância justifica seu medo. Ironicamente, este medo, num entremeio entre a grandiloquência das violências e humilhações raciais em sua memória e a tragédia hiperbólica de sua morte, manifesta-se no tímido e constrangido receio de que o maitre do restaurante se recuse a servi-lo (VERISSIMO, 2008, p. 60).

É no episódio da tortura, após a morte de sua amada K. na explosão do café Caravelle, que as ambiguidades e definições mobilizadas até então ganham, para o tenente, uma concretude intolerável. Responsável por conduzir o inter- 
rogatório do prisioneiro, a fim de adquirir informações sobre uma segunda bomba, o tenente tem, diante de si, além do inimigo, um tradutor intérprete e um sargento que, de acordo com o coronel, "na vida civil, foi funcionário da polícia e tem prática... desse... dessas coisas" (VERISSIMO, 2008, p. 107). A apresentação do sargento, feita pelo comandante, corrobora suas claras insinuações, anteriores e posteriores, como as de que o interrogatório "será feito sob o maior sigilo", sem "nenhuma autoridade local e especialmente nenhum correspondente de guerra, nosso ou estrangeiro" e de que "interessam resultados e não métodos" (VERISSIMO, 2008, p. 107).

Ciente de que o coronel o havia induzido "a usar até a violência" sem, no entanto, autorizá-lo expressamente, o jovem vê-se diante de uma situação inescapável. Especialista em fugas, o tenente não pode demandar, nem do coronel nem do major, a ordem taxativa que de si the demandaria, mais tarde, o sargento. Oficial de um exército que na busca pelos guerrilheiros calcinava plantações e florestas e, nelas, o que mais houvesse de vida, o tenente torna-se protagonista de um procedimento de violação humana que nas suas palestras à professora eram conteúdo meramente abstrato de uma guerra necessária para a tutela de uma sociedade atrasada. O jovem de quem precisa extrair informações é um rosto humano para a clivagem entre, de um lado, a morte de pessoas inocentes - como sua K. - e, de outro, a desonra.

"Mas você não acha que, a esta altura dos acontecimentos, dum modo ou de outro, já estamos todos um tanto desonrados?" (VERISSIMO, 2008, p. 108), pergunta-lhe o major, ao que 0 tenente, num arroubo de clareza e segurança intelectual, declara-se preso a uma armadilha. "As Forças Armadas são uma espécie de corpo mistico. Eu sou um individuo. Dentro de poucas horas, um civil. E sempre, irremediavelmente, um negro. O coronel encontrou o álibi perfeito para si mesmo e para o exército".

Mais de um século antes das elegantes, tautológicas e produtivas mitologias freudianas do inconsciente, Immanuel Kant, em sua Fundamentação da metafisica dos costumes, observou que o juízo do sujeito acerca das motivações de suas condutas é impreciso. Para Kant, há uma intransponivel opacidade motivacional quando a norma, oferecida pelo imperativo categórico, fórmula que rege a conduta ética dos seres racionais, constrange o individuo a uma ação que the é, por outras razões, que não as da moralidade, conveniente. Ou seja, é impossivel avaliar o caráter moral das motivações do individuo para determinada ação para a qual convirjam, além do dever moral, conveniências de outra ordem. Não se pode, diz Kant, "nem mesmo mediante o mais escrupuloso dos exames, devassar totalmente as molas propulsoras secretas" (KANT, 2013, p. 403) da vontade.

Os excessos do sargento que, ao contrário do tenente, soube solicitar uma ordem expressa para perpetrar os designios do coronel, acarretam a morte do prisioneiro. O médico judeu que atesta o óbito do prisioneiro não pode compactuar com o acobertamento do assassinato, deixando ao tenente perspectivas bastante limitadas de fuga. Suas escolhas, das quais resultaram a morte do jovem asiático, podem ser escrutinadas à luz do amor por K. e da raiva decorrente de sua morte, da expectativa de salvar vidas, vingar a amada ou ainda por sua submissão tanto ao coronel, seu superior, quanto, de alguma forma, ao sargento, seu subalterno. A identificação disso que Kant chamou de molas propulsoras são uma necessidade da alma humana na produção de um conhecimento sobre sua própria natureza e para o qual a literatura tem oferecido as mais rigorosas e eficientes fenomenologias. Quantificá-las ou tomá-las como substrato de legitimidade para ações políticas é extrapolar sua natureza interpretativa, portanto, invariavelmente arbitrária, e emocional.

A morte do tenente é o desfecho inevitável quando as inacabáveis fugas de sua condição de negro encontram termo na constatação de que a mecânica do racismo sistemático fará recair sobre si toda a responsabilidade sobre a tortura e a morte de um jovem a quem os direitos póstumos da dignidade de um julgamento são a irônico e desaforado contraponto à realidade brutal de um país dilacerado pelo totalitarismo e pela intervenção estrangeira. 
Contrapondo, de um lado, o chauvinismo intelectual do coronel às cínicas relativizações do major e, de outro, as inseguranças do tenente às peremptórias e caricaturalmente lúcidas altercações da professora, Erico Verissimo compôs uma obra em que a profusão de sentidos para as ações humanas é explorada, reflexivamente, sem o delírio pretensioso de resumir os componentes factuais de uma trama em que as violações do homem e de sua liberdade não podem ser expurgadas por ingênuas declarações de interesse.

Resultado mais de suas bem-acabadas ironias estruturais do que de suas prédicas, o legado literário de O prisioneiro é o testemunho sensivel da crença inabalável do autor na capacidade humana de pôr a inteligência a serviço da dignidade de homens e mulheres. É, também, o registro de que a honestidade intelectual é mais eficaz resposta à estupidez e deve ser anterior a todas as aspirações e vaidades da razão.

\section{Referências}

KANT, Immanuel. Fundamentação da metafísica dos costumes. Petrópolis: Vozes, 2013.

KIRK, Geoffrey; RAVEN, John Earle; SCHOFIELD, Malcolm. Os filósofos pré-socráticos. Lisboa: Fundação Calouste Gulbenkian, 2010.

LYOTARD, Jean-François. A condição pós-moderna. Rio de Janeiro: José Olympio, 1986.

MARTIN, Kathleen. O livro dos simbolos: reflexões sobre imagens arquetípicas. Colônia: Taschen, 2012.

TUTIKIAN, Jane. Os restelos do século do fascinio: a renúncia ao épico. Signo, Santa Cruz do Sul, v. 26, n. 41, p. 17, set. 2019. ISSN 1982-2014.

VALÉRY, Paul. L'idée fixe. Paris: La Pléiade, 1960. (Oeuvres complètes. Tome II).

VERISSIMO, Erico. O prisioneiro. São Paulo: Companhia, das Letras, 2008.

VERISSIMO, Erico. Saga. Porto Alegre: Globo, 1995.

\section{Benhur Bortolotto}

Graduado em Filosofia pela Universidade Federal do Rio Grande do Sul (UFRGS), em Porto Alegre, RS, Brasil; doutorando em Literatura pela mesma universidade.

\section{Endereço para correspondência}

Benhur Bortolotto

Universidade Federal do Rio Grande do Sul

Av. Bento Gonçalves, 9500, Prédio 4.3221, sala 122

Agronomia, 91501-970

Porto Alegre, RS, Brasil

Os textos deste artigo foram revisados pela Poá Comunicação e submetidos para validação do autor antes da publicação. 